\title{
Randomized Prospective Single-Blinded Study of TEP Inguinal Hernia Repair: Tacking Mesh versus Self- Fixating Mesh
}

\author{
AlJ amal Y*, Buckarma EL, Gas B, Abdelsattar J \\ and Farley D \\ Department of General Surgery, Mayo Clinic, USA \\ *Corresponding author: Yazan AlJ amal, Department \\ of General Surgery, Division of Colon and Rectal Surgery, \\ Mayo Clinic, 200 First S SW, Rochester, MN 55905, \\ Minnesota, USA
}

Received: November 27, 2017; Accepted: December 21, 2017; Published: December 28, 2017

\begin{abstract}
Background: Totally extra peritoneal inguinal hernia repair (TEP-IHR) offers advantages over conventional open IHR. ProGrip ${ }^{\mathrm{TM}}$ self-fixating mesh delivers a tack-free fixation repair. Using ProGrip ${ }^{\mathrm{TM}}$ during TEP-IHR may lead to decreased postoperative pain and/or complications compared to fixating mesh with titanium clips.
\end{abstract}

Methods: A randomized, prospective, single-blinded study compared ProGrip ${ }^{\mathrm{TM}}$ mesh versus regular Prolene mesh with titanium tack fixation. A total of 38 patients underwent 65 TEP-IHR at our institution. All repairs were completed with either Prolene mesh (Group TT = 19 patients) with tack fixation or ProGrip ${ }^{\mathrm{TM}}$ self-fixating mesh (Group PG $=19$ patients). Blinded patients were asked to rate their level of pain according to a Likert scale $(0=$ no pain, $5=$ severe pain) preoperatively, and at 1 and 4 weeks postoperatively.

Results: Thirty eight men underwent 65 TEP-IHR with a mean age of 55 years $(S D \pm 11)$, mean $B M I$ of $30 \mathrm{~kg} / \mathrm{m}^{2}(S D \pm 9)$ and mean ASA of 1.9 (SD \pm 0.5 ). Most repairs were bilateral $(T T=16, P G=11)$. Operative times $(T T=65$ $\min \pm 18$; $P G=77 \min \pm 31, p=0.1$ ), hospital length of stay (15.7 vs. 14.4 hours, $\mathrm{p}=0.63)$, and urinary retention $(\mathrm{TT}=1, \mathrm{PG}=1, \mathrm{p}=\mathrm{NS}$ ) were similar. No significant differences occurred in the level of pain or limitation of movement pre-op and 4 weeks postop. The patients in TT group reported more pain and limitation of movement than the patients in PG group at 1 week postop $(p=0.02)$.

Conclusion: ProGrip ${ }^{\mathrm{TM}}$ self-fixating mesh for TEP-IH repair appears safe and effective; it has similar performance to Prolene mesh using titanium tack fixation.

\section{Introduction}

Hernia repairs represent one of the most common surgical operations performed worldwide [1]. While there are multiple methods to fix inguinal herniae, a tension-free repair is the procedure of choice [2]. Endoscopic inguinal herniorrhaphy has become an established approach to repair groin herniae. Totally extra peritoneal inguinal hernia repair (TEP-IHR) offers advantages over conventional open IHR: preperitoneal approach with potentially less discomfort, less morbidity, and the easy option for bilateral repairs [3,4]. Different types of mesh and fixation methods have been described to avoid in guinodynia with limited success $[5,6]$. Recently, a self-fixating mesh has been introduced and used successfully in open and MIS inguinal hernia repairs [7-9]. It is made of monofilament polyester with restorable grips on one side to allow positioning and fixation of the mesh to the surrounding tissue and collagen film on the other side to facilitate mesh handling and deployment $[10,11]$. We questioned whether using self-fixating mesh during TEP-IHR would lead to decreased postoperative pain and complications compared to fixating mesh with titanium tacks.

\section{Methods}

With approval of our Institutional Review Board, a randomized, prospective, single-blinded study of 38 patients was used to compare self-fixating mesh versus regular Prolene mesh with titanium tacks performed by one surgeon and his surgical team at the Mayo Clinic, Table 1: Patient demographics and intraoperative findings.

\begin{tabular}{|c|c|c|c|}
\hline & Prolene & ProGrip $^{\text {TM }}$ & p value \\
\hline Age & $58 \pm 11$ & $55 \pm 11$ & 0.5 \\
\hline BMI & $30 \pm 10$ & $30 \pm 4$ & 0.9 \\
\hline ASA & \multicolumn{2}{|c|}{$1.7 \pm 0.5$} & 0.1 \\
\hline Site Hernia & \multicolumn{3}{|c|}{} \\
\hline Bilateral & $3(16 \%)$ & $8(42 \%)$ & \\
\hline Total Hernias & $16(84 \%)$ & $11(58 \%)$ & 0.1 \\
\hline Direct & 36 & 30 & \\
\hline Indirect & 25 & 19 & \\
\hline Femoral & 8 & 8 & 1 \\
\hline Pantaloon & 1 & 0 & \\
\hline Type Hernia & 2 & 3 & \\
\hline Primary & 16 & 3 & \\
\hline Recurrent & 3 & & \\
\hline & & & \\
\hline
\end{tabular}

Austin J Surg - Volume 4 Issue 5 - 2017

ISSN : 2381-9030 | www.austinpublishinggroup.com

AlJamal et al. () All rights are reserved
Citation: AlJamal Y, Buckarma EL, Gas B, Abdelsattar J and Farley D. Randomized Prospective Single-Blinded Study of TEP Inguinal Hernia Repair: Tacking Mesh versus Self-Fixating Mesh. Austin J Surg. 2017; 4(5): 1117. 
Table 2: Operative outcomes by group.

\begin{tabular}{|c|c|c|c|}
\hline & Prolene & ProGrip ${ }^{\mathrm{TM}}$ & $p$ value \\
\hline \multicolumn{4}{|l|}{ Operative time (min) } \\
\hline Bilateral & $69 \pm 6.5$ & $84 \pm 7.8$ & 0.17 \\
\hline Unilateral & $40 \pm 12$ & $66 \pm 7$ & 0.09 \\
\hline $\begin{array}{l}\text { OR start time } \\
\text { (time, range) }\end{array}$ & 8:59 am ( 8:08 am, 14:24 am) & 8:57 am ( 8:04 am, 12:48 am) & NA \\
\hline LOS (hrs) & $14 \pm 5$ & $16 \pm 5$ & 0.5 \\
\hline Admit & 2 & 1 & 0.6 \\
\hline Post op Narcotics (morphine equivalent) & $21 \pm 44$ & $63 \pm 53$ & $0.01^{*}$ \\
\hline Follow Up & 8.6 & 9.1 & 0.8 \\
\hline Urinary Retention & 1 & 1 & 1.0 \\
\hline Recurrence & 0 & 1 & NA \\
\hline
\end{tabular}

Table 3: Survey results per question among groups; Pain.

\begin{tabular}{|c|c|c|c|c|c|c|c|c|}
\hline & & $\begin{array}{c}\text { Q1: Pain } \\
\text { while laying } \\
\text { down }\end{array}$ & $\begin{array}{l}\text { Q2: Pain while } \\
\text { bending over }\end{array}$ & $\begin{array}{l}\text { Q3: Pain while } \\
\text { performing activities } \\
\text { of daily living }\end{array}$ & $\begin{array}{l}\text { Q4: Pain when } \\
\text { coughing or deep } \\
\text { breathing }\end{array}$ & $\begin{array}{c}\text { Q5: Pain } \\
\text { while walking }\end{array}$ & $\begin{array}{c}\text { Q6: Pain while } \\
\text { walking up the } \\
\text { stairs }\end{array}$ & $\begin{array}{l}\text { Q7: Pain while } \\
\text { exercising }\end{array}$ \\
\hline \multirow{2}{*}{ Pre-Op } & Prolene & $0.89 / 5$ & 0.736 & 1.262 & 1.25 & 1.25 & 1.1 & 1.47 \\
\hline & ProGrip $^{\mathrm{TM}}$ & 1.04 & 1.58 & 1.62 & 1.89 & 1.53 & 1.63 & 1.84 \\
\hline \multirow{2}{*}{$\begin{array}{c}1 \text { wk } \\
\text { Postop }\end{array}$} & Prolene & 1.15 & 1.578 & 1.523 & 1.31 & 0.996 & 0.78 & 0.37 \\
\hline & ProGrip $^{\mathrm{TM}}$ & 0.81 & 1.26 & 0.93 & 0.79 & 0.95 & 0.79 & 0.26 \\
\hline \multirow{2}{*}{$\begin{array}{c}4 \text { wk } \\
\text { Postop }\end{array}$} & Prolene & 0 & 0.366 & 0.158 & 0.105 & 0 & 0 & 0.26 \\
\hline & ProGrip $^{\mathrm{TM}}$ & 0.21 & 0.36 & 0.25 & 0.47 & 0.47 & 0.263 & 0.05 \\
\hline
\end{tabular}

Table 4: Survey results per question among groups; movement limitation.

\begin{tabular}{|c|c|c|c|c|c|c|}
\hline & & $\begin{array}{l}\text { Q1: Movement } \\
\text { limitation while } \\
\text { bending over }\end{array}$ & $\begin{array}{c}\text { Q2: Movement limitation } \\
\text { while performing activities of } \\
\text { daily living }\end{array}$ & $\begin{array}{l}\text { Q3: Movement } \\
\text { limitation while } \\
\text { walking }\end{array}$ & $\begin{array}{l}\text { Q4: Movement limitation } \\
\text { while walking up the } \\
\text { stairs }\end{array}$ & $\begin{array}{l}\text { Q5: Movement } \\
\text { limitation while } \\
\text { exercising }\end{array}$ \\
\hline \multirow{2}{*}{ Pre-Op } & Prolene & 1.052 & 1.26 & 1.53 & 1 & 1.57 \\
\hline & ProGrip $^{\mathrm{TM}}$ & 1.89 & 1.62 & 1.21 & 1 & 1.142 \\
\hline \multirow{2}{*}{$\begin{array}{c}1 \text { wk } \\
\text { Postop }\end{array}$} & Prolene & 1.42 & 1.52 & 0.68 & 0.73 & 0.157 \\
\hline & ProGrip ${ }^{\mathrm{TM}}$ & 0.89 & 0.93 & 0.5 & 0.47 & 0.05 \\
\hline \multirow{2}{*}{$\begin{array}{c}4 \text { wk } \\
\text { Postop }\end{array}$} & Prolene & 0.052 & 0.158 & 0 & 0 & 0.05 \\
\hline & ProGrip ${ }^{\mathrm{TM}}$ & 0.37 & 0.25 & 0.21 & 0.21 & 0.05 \\
\hline
\end{tabular}

Rochester MN from December 2013 to November 2015. All males between the ages of 18 and 100 years of age undergoing TEP-IHR were eligible.

Baseline demographics and perioperative data were extracted from the medical records, including: age, gender, body mass index $\left(\mathrm{BMI}\right.$ in $\mathrm{kg} / \mathrm{m}^{2}$ ), previous inguinal hernia operations, laterality and type of hernia, length of operation, total amount of hours spent in the hospital, amount of pain medication administered (converted to morphine equivalents), conversion rates, intra-operative complications, postoperative surgical complications (e.g., wound infection, hematoma), and general postoperative complications (e.g., pneumonia, urinary tract infection, pulmonary embolism). Followup data were obtained through review of the medical record (e.g., postoperative return visits), including long term issues and hernia recurrence.

Blinded patients were asked to rate their level of pain on a Likert scale ( 0 through $5 ; 0=$ no pain, $5=$ severe pain) preoperatively, and at 1 and 4 weeks, postoperatively. In follow-up, we used a standardized telephone script consisting of 12 questions, and asked for symptoms such as pain and limitation of movement while lying down, bending over, sitting up, coughing, taking a deep breath, walking upstairs and performing activities of daily living.

TEP-IHR was performed under general anesthesia, using a 3-port, midline technique (one infraumbilical 10-mm Hasson trocar, two 6-mm trocars). A balloon dissector and blunt dissection expose the preperitoneal space of Bogros. Placement of Prolene mesh $(10 \times$ $15 \mathrm{~cm}$ ) fixed with titanium tacks or ProGrip ${ }^{\mathrm{TM}}$ self-fixating mesh (10 $\times 15 \mathrm{~cm}$ ) was utilized to widely cover hernia defects.

Because of data distribution, comparisons between groups were performed with nonparametric tests as appropriate. All statistical tests were two-sided, and a $p$ value of 0.05 was considered statistically significant. Continuous data are presented as means with Standard Deviation (SD) or median (range), and categorical data are presented as counts and percentages. All statistical analyses were performed using JMP software (version 9.0.1; SAS, Cary, NC). 


\section{Results}

Thirty eight male patients underwent 65 TEP-IHR. The selffixating ProGrip ${ }^{\mathrm{TM}}$ mesh (PG) group $(\mathrm{n}=19)$ and regular Prolene mesh with Titanium Tacks (TT) group $(n=19)$ were similar: mean (SD) age was 55 years $( \pm 11)$ in PG and 58 years $( \pm 11)$ in TT $(\mathrm{p}=\mathrm{NS})$; mean (SD) BMI was $30 \mathrm{Kg} / \mathrm{m}^{2}( \pm 4)$ in PG and $30 \mathrm{Kg} / \mathrm{m}^{2}( \pm 10)$ in TT, $(\mathrm{p}=\mathrm{NS})$. Mean (SD) ASA was $1.7( \pm 0.5)$ in both groups. Most repairs were bilateral $(\mathrm{TT}=16, \mathrm{PG}=11, \mathrm{p}=\mathrm{NS}$, Table 1$)$.

No significant intra operative complications were encountered the median (range) starting time of operation was 8:59 am (8:08, 14:24) for TT and 8:57 am $(8: 04,12: 48)$ for PG. The mean (SD) operative time for bilateral repairs was $69( \pm 6.5)$ minutes for TT and $84( \pm 7.8)$ minutes for $\mathrm{PG}(\mathrm{p}=0.17)$. The mean (SD) operative time for unilateral repairs was $40( \pm 12)$ minutes for TT and $66( \pm 7)$ minutes for PG $(p=0.09)$. During their hospitalization, PG patientsrequired more pain medication (morphine equivalents) than TT patients (63 $\mathrm{mg}( \pm 5.3)$ vs. $21 \mathrm{mg}( \pm 4.4)$, respectively; $p=0.01)$. Mean (SD) hospital length of stay was $15.7( \pm 1.5)$ hours for TT and $14.4( \pm 1.5)$ hours for PG. Three patients stayed overnight $(\mathrm{TT}=2$ for bladder catheterization due to urinary retention and pain management; $\mathrm{PG}=1$ for bladder catheterization due to urinary retention) (Table 2). One TT patient required antibiotics for a minor superficial skin infection at the umbilical port site, and one recurrence was identified in the PG group over the median time of observation of 12 months. No recurrence was seen in TT patients ( $\mathrm{p}=\mathrm{NS}$ ).

All patients (100\%) responded to our pre-operative, 1 week and 4 week postoperative surveys. Hernia repair improved the pain and the movement limitation in patients in both groups. Overall, Twentyseven patients $(74 \%)$ reported some type of pain preoperatively compared to 10 patients (25\%) who reported some type of pain at 4 weeks postoperatively, $\mathrm{p}<0.05$. Moreover, $26(68 \%)$ patients reported some limitation of movement preoperatively compared to only 4 $(10 \%)$ patients at 4 weeks postoperatively; $\mathrm{p}<0.05$.

There was no difference in the level of pain preoperatively between the two groups $(\mathrm{TT}=1.3 / 5, \mathrm{PG}=1.6 / 5 ; \mathrm{p}=0.2)$.TT patients reported a higher pain score than PG patients at 1 week postoperatively (TT=1.1/5, PG=0.8/5; $\mathrm{p}=0.02$ ).No difference in the level of pain 4 weeks postoperatively was reported between groups $(\mathrm{TT}=0.1 / 5$, $\mathrm{PG}=0.3 / 5 ; \mathrm{p}=0.1$ ) (Table 3 and Figure 1 ).

There was no difference between groups preoperatively in movement limitation ( $\mathrm{TT}=1.3 / 5, \mathrm{PG}=1.4 / 5 ; \mathrm{p}=0.6)$. TT patients reported more movement limitationat 1 week postoperatively compared to $\mathrm{PG}$ patients ( $\mathrm{TT}=0.84 / 5, \mathrm{PG}=0.53 / 5 ; \mathrm{p}=0.01$ ). There was no difference in movement limitations between groups at 4 weeks postoperatively ( $\mathrm{TT}=0.12 / 5, \mathrm{PG}=0.2 / 5 ; \mathrm{p}=0.5)($ Table 4 and Figure 2$)$.

\section{Discussion}

This randomized prospective, single blinded study of 38 patients undergoing TEP IH repairs suggests: 1) ProGrip ${ }^{\text {pos }}$ self-fixating mesh for TEP-IHR is safe and effective, 2) it has similar operative times and outcomes to Prolene mesh using titanium tacks, 3) ProGrip patients ingested more narcotic medication postoperatively than Prolene patients, and 4 )the pain and limitation movement scores at one week postoperatively were higher for the TT patients, but there

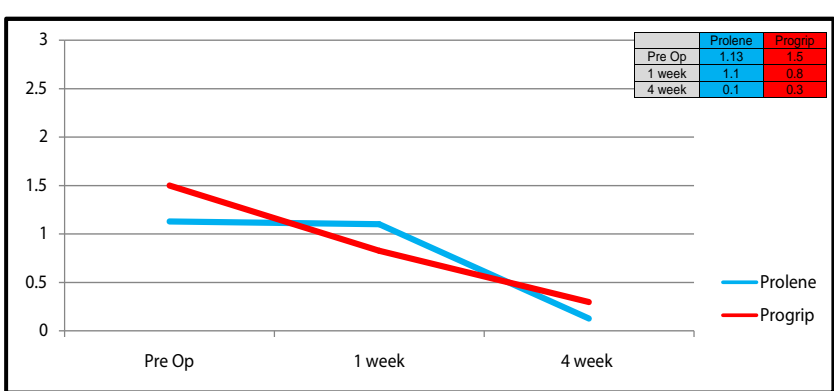

Figure 1: Survey results among groups (pain).

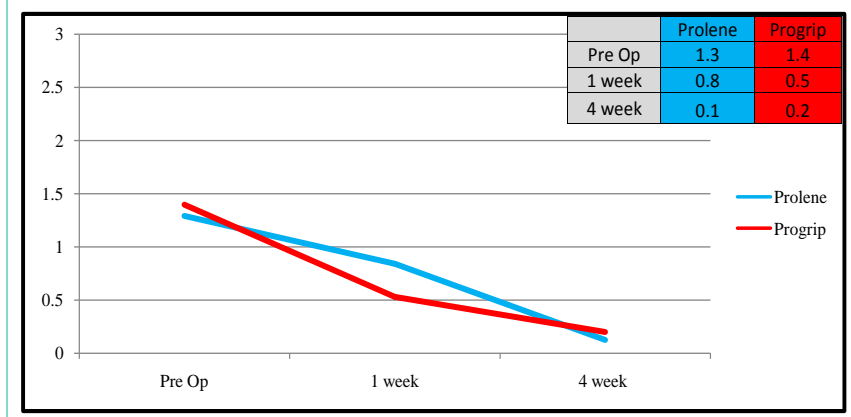

Figure 2: Survey results among groups (movement limitation).

was no difference in pain and limitation movement scores at 4 weeks.

ProGrip $^{\mathrm{mm}}$ self-fixating mesh is a tack-free fixation mesh for use in open \& laparoscopic hernia repairs. It is composed of absorbable Monofilament Polylactic Acid micro grips on one surface integrated with a lightweight Monofilament Polyethylene Terephthalate. The micro grips act as a kind of "Velcro" to the soft tissue surfaces resulting in self-fixation. Initial studies have shown that this mesh is safe for use in both TEP and open inguinal hernia repair [12]. While slightly more expensive than plain Prolene mesh, ProGrip ${ }^{\text {twx }}$ mesh does not require the expense of titanium tackers [13]. In our study using tacks was faster than placing ProGrip ${ }^{\mathrm{rx}}$, but not significantly so.

The difficult part of using ProGrip ${ }^{\text {in }}$ is moving the mesh within the confined preperitoneal space. It can be challenging: It is not always easy to move the fixating mesh over the cord structures, the hernia sac and surrounding fat. However with repetition, handling the mesh becomes easier and takes less time. Developing wide exposure and maximizing the preperitoneal space facilitates easier placement.

One recurrence was encountered in our study: a ProGrip ${ }^{\text {Th }}$ patient presented 6 months later with a left sided recurrent inguinal hernia after undergoing TEP IHR for large incarcerated bilateral indirect herniae. The dissection and hernia reduction were difficult in this patient, but the mesh panels was placed in satisfactory positions. Reexploration has not yet been performed, and we remain unclear why recurrence occurred on the patient's left side.

In a meta-analysis, Lau and Patil recommended fixation of mesh routinely, especially in large hernias $(>3 \mathrm{~cm})[14,15]$. However, fixating mesh using tacks for smaller defects has been controversial due to the concerns of an increasing incidence of pain and concerns of recurrence with no fixation [16,17]. Our group published a 
prospective study in 2006 that showed a significant reduction in the use of postoperative narcotic analgesia, hospital length of stay, the development of postoperative urinary retention, as well as no increase in recurrence rate by eliminating tack fixation of mesh during laparoscopic TEP-IHR [18]. Another study compared the use of Fibrin sealant with tack fixation in laparoscopic TEP inguinal hernia repair and found there was no advantage in using one technique over the other [19]. Moreover, in the most recent meta-analysis by Cristaudo and his group, there were no differences in (Carolina Comfort Scale) scores when comparing types of mesh, configuration of the mesh or fixation methods [20].

Others have found most patients undergoing laparoscopic $\mathrm{IH}$ repairs $[21,22]$ recover quickly and have less pain with activity than they did preoperatively. We are encouraged that this small study similarly confirms superb outcomes in short follow up for both ProGrip and tacking options. Surgeons should feel confident that both options offer effective repair for their patients.

This prospective study has several limitations. The small size of patients in both groups limits the power to reflect statistical differences. This study had a large number of bilateral repairs reflecting the inherent referral bias of our practice. Furthermore, we recognize that survey scores were consistently very low preoperatively, at 1 week and at 4 weeks postoperatively for both groups; statistical differences may have been identified, but clinical relevance may be negligible.

In summary, this small prospective, randomized study, confirms several known findings about patients undergoing TEP-IHR: 1) most had less pain and greater freedom of movement following the procedure (with tacks or ProGrip) and 2) ProGrip ${ }^{\text {Twe }}$ self-fixating mesh as a reasonable option to Prolene mesh tacked with Titanium clips. It will take much larger randomized trials with longer follow-up to confirm our findings.

\section{References}

1. Awad SS, Fagan SP. Current approaches to inguinal hernia repair. Am J Surg. 2004; 188: 9S-16S

2. Eklund AS, Montgomery AK, Rasmussen IC, Sandbue RP, Bergkvis LA, Rudberg CR. Low recurrence rate after laparoscopic (TEP) and open (Lichtenstein) inguinal hernia repair: a randomized, multicenter trial with 5-year follow- up. Ann Surg. 2009; 249: 33-38.

3. McCormack K, Scott NW, Go PM, Ross S, Grant AM. Laparoscopic techniques versus open techniques for inguinal hernia repair. Cochrane Database Syst Rev. 2003; 1: CD001785.

4. McCormack K, Scott NW, Go PM, Ross S, Grant AM. Laparoscopic techniques versus open techniques for inguinal hernia repair. Cochrane Database Syst Rev. 2003; 1: CD001785.

5. Koch CA, Greenlee SM, Larson DR, Harrington JR, Farley DR. Randomized Prospective Study of Totally Extra peritoneal Inguinal Hernia Repair: Fixation versus no fixation of Mesh. JSLS. 2006; 10: 457-460.

6. Tam KW, Liang $\mathrm{HH}$, Chai $\mathrm{CY}$. Outcomes of staple fixation of mesh versus nonfixation in laparoscopic total extraperitoneal inguinal repair: a metaanalysis of randomized controlled trials. World J Surg. 2010; 34: 3065-3074.

7. P Chastan. Tension-Free Open Hernia Repair Using an Innovative SelfGripping Semi-Resorbable Mesh," Hernia. 2009; 13: 137-142.

8. M. Kapischke, H. Schulze, A. Caliebe. Self-Fixating Mesh for the Lichtenstein Procedure-A Prestudy. Langenbeck's Archives of Surgery. 2010; 395: 317 322.

9. Messaris E, Nicastri G, Dudrick SJ. Total Extra peritoneal Laparoscopic Inguinal Hernia Repair without Mesh Fixation: Prospective Study with 1-Year Follow Up Results. Archives of Surgery. 2010; 145: 334-338.

10. Kolbe T, C Hollinsky, I Walter, A Joachim, T Rülicke. Influence of a New SelfGripping Hernia Mesh on Male Fertility in a Rat Model. Surgical Endoscopy. 2009; 24: 455-461.

11. C Hollinsky, T Kolbe, I Walter, A Joachim, S Sandberg, T Koch, T Rülicke Comparison of a New Self Gripping Mesh with Other Fixation Methods for Laparoscopic Hernia Repair in a Rat Model. Journal of the American College of Surgeons. 2009; 208: 1107-1114.

12. Information's derived from ProGrip Laparoscopic Self- Fixating Mesh Information sheet. (c) 2012 Covidien 11.12 M120886

13. Estimate derived from Mayo Clinic Hospital Supply service. Based on typical prices of anatomical mesh and absorbable fixation in the US.

14. YJ Teng, SM Pan, YL Liu, KH Yang, YC Zhang, JH Tian, et al. A meta analysis of randomized controlled trials of fixation versus nonfixation of meshin laparoscopic total extra peritoneal inguinal hernia repair, Surg. Endosc. 2011; 25: 2849-2858

15. MS Sajid, N Ladwa, L Kalra, K Hutson, P Sains, MK Baig. A meta-analysis examining the use of tacker fixation vs no-fixation of mesh in laparoscopic inguinal hernia repair. Int J Surg. 2012; 10: 224-231.

16. JC Lantis, SD Schwaitzberg. Tack entrapment of the ilioinguinal nerve during laparoscopic hernia repair. J Laparoendosc Adv Surg Tech. 1999; 9: 285289

17. C Taylor, L Layani, V Liew, M Ghusn, N Crampton, S White. Laparoscopic inguinal hernia repair without mesh fixation. Surg Endosc. 2008; 22: 757-762.

18. Cody A Koch, Susan M Greenlee, Dirk R Larson, Jeffrey R Harrington, David R Farley. Randomized Prospective Study of Totally Extraperitoneal Inguinal Hernia Repair: Fixation Versus No Fixation of Mesh: JSLS. 2006; 10: $457-$ 460.

19. CA Koch, SM Greenlee, DR Larson, JR. Harrington, DR Farley, Randomized prospective study of totally extraperitoneal inguinal hernia repair: fixationversus no fixation of mesh. JSLS. 2006; 10: 457-460.

20. ArunNayak b, Sarah Martin c, Reza Adib d, Ian Martin b. A prospective randomized trial comparing mesh types and fixation in totally extraperitoneal inguinal hernia repairs Adam Cristaudo.

21. Shahzad M Ali, David R Farley, Zendejas B, Yadav S, Hernandez-Irizarry RC, Lohse CM. Predictors of Chronic Groin Discomfort afterLaparoscopic Totally Extraperitoneal InguinalHernia Repair. 2013 by the American College of Surgeons. 2013; 217: 72-78.

22. McCormack K, Scott NW, Go PM, Ross S, Grant AM. Laparoscopic techniques versus open techniques for inguinal hernia repair. Cochrane Database Syst Rev. 2003; 1: CD001785.
Austin J Surg - Volume 4 Issue 5 - 2017

ISSN : 2381-9030 | www.austinpublishinggroup.com

AlJamal et al. (C) All rights are reserved
Citation: AlJamal Y, Buckarma EL, Gas B, Abdelsattar J and Farley D. Randomized Prospective Single-Blinded Study of TEP Inguinal Hernia Repair: Tacking Mesh versus Self-Fixating Mesh. Austin J Surg. 2017; 4(5): 1117. 